\title{
Common fixed point results in cone metric spaces
}

\author{
S. K. Tiwari ${ }^{1}$, R. P. Dubey ${ }^{2}$, A. K. Dubey ${ }^{3}$ \\ ${ }^{1,2}$ Department of Mathematics, Dr. C. V. Raman University Bilaspur, Chhattisgarh - 495113 India \\ ${ }^{3}$ Department of Mathematics, Bhilai Institute of Technology, Bhilai House, Durg 491001, India \\ *Corresponding author E-mail : sk10tiwari@gmail.com
}

\begin{abstract}
In this paper, we generalize and prove common fixed point theorems of generalized contractive maps in complete cone metric spaces. Our theorems improve and generalize of the results [7].
\end{abstract}

Keywords: Complete cone metric space, common fixed point, Generalized contractive Mapping, Non-normal cone.

\section{Introduction}

Recently, Huang and Zhang [1], replaced the real numbers by an ordering Banach space, and defined a cone metric $\operatorname{spaces}(X, d)$ of contractive mappings and also discussed some properties of convergence of sequences; many authors have established and extend different types of contractive mappings in cone metric spaces see for instance [3-10]., and also generalized the results [1] by [2].The author [7] proved fixed point results in cone metric spaces.

The purpose of this paper is to obtain the generalization of results in [1] and 2.1, 2.2 of [7], by using non-normality of cone.

\section{Preliminary notes}

First, we recall some standard notations and definitions in cone metric spaces with some of their properties [1].

Definition 2.1 [1]: Let $E$ be a real Banach space and $P$ be a subset of $E$. $P$ is called a cone if and only if:

(i) $P$ is closed, non - empty and $P \neq\{0\}$,

(ii) $\mathrm{a} x+\mathrm{b} y \in P$ for all $x, y \in P$ and non - negative real number a, b;

(iii) $x \in P$ and $-x \in P \Rightarrow x=0 \Longleftrightarrow P \cap(-P)=\{0\}$.

Given a cone $P \subset E$, we define a partial ordering $\leq$ on E with respect to $P$ by $x \leq y$ if and only if $y-x \in P$. We shall write $x \ll$ y if $y-x \in \operatorname{int} P$, where int $P$ denotes the interior of $P$.

The cone $P$ is called normal if there is a number $\mathrm{K}>0$ such that $x, y \in \mathrm{E}, 0 \leq \mathrm{x} \leq \mathrm{y}$ implies $\|x\| \leq K\|y\|$.

The least positive number satisfying the above is called the normal constant $\mathrm{P}$. The cone $\mathrm{p}$ is called regular if every increasing sequence which is bounded from above is convergent that is, if $\left\{x_{n}\right\}$ is sequence such that $x_{1} \leq x_{2} \leq \ldots x_{\mathrm{n}}$ $\leq \ldots \leq y$ for some $y \in E$, then there is $x \in E$ such that $\left\|x_{n-} x\right\| \rightarrow 0(n \rightarrow \infty)$. Equivalently the cone $p$ is regular if and only if every decreasing sequence which is bounded from below is convergent.

Lemma 2.2[2, 8]

(i) Every regular cone is normal

(ii) For each $\mathrm{k}>1$, there is a normal cone with normal constant $\mathrm{K}>\mathrm{k}$.

Definition 2.3[1]: Let $X$ be a non - empty set. Suppose the mapping $d: X x X \rightarrow E$ satisfies

(i) $0<d(x, y)$ for all $x, y \in \mathrm{X}$ and $\mathrm{d}(x)=$,0 if and only if $x=y$,

(ii) $d(x, y)=d(y, x)$ for all $x, y \in X$;

(iii) $d(x, y) \leq d(x, \mathrm{z})+d(\mathrm{z}, y)$ for all $x, y \in \mathrm{X}$.

Then $d$ is called a cone metric, on $\mathrm{X}$ and pair $(X, d)$ is called a cone metric space. It is obvious that cone metric spaces generalize metric space. 
Example 2.4: Let $E=R^{2}, P=\{(x, y) \in E: x, y \geq 0\}, X=R$ and $d: X \times X \rightarrow$ E defined by $d(x, y)=(|x-y|, \alpha|x, y|)$, where $\alpha \geq 0$ is a constant. Then $(X, d)$ is a cone metric space.

Definition 2.5 [1]: Let $(X, d)$ be a cone metric space, $x \in \mathrm{X}$ and $\left\{x_{\mathrm{n}}\right\}_{\mathrm{n} \geq 1}$ a sequence in $\mathrm{X}$. Then,

(i) $\left\{x_{\mathrm{n}}\right\}_{\mathrm{n} \geq 1}$ converges to $\mathrm{x}$ whenever for every $\mathrm{c} \in \mathrm{E}$ with $\mathrm{o} \ll \mathrm{c}$, there is a natural number $\mathrm{N}$ such that $\mathrm{d}\left(x_{\mathrm{n}}, x\right)$ $\ll \mathrm{c}$ for all $\mathrm{n} \geq \mathrm{N}$. We denote this by $\lim _{\mathrm{n} \rightarrow \infty} x_{\mathrm{n}}=x$ or $x_{\mathrm{n}} \rightarrow x,(\mathrm{n} \rightarrow \infty)$.

(ii) $\left\{x_{\mathrm{n}}\right\}_{\mathrm{n} \geq 1}$ is said to be a Cauchy sequence if for every $\mathrm{c} \in \mathrm{E}$ with $\mathrm{o} \ll \mathrm{c}$, there is a natural number $\mathrm{N}$ such that $\mathrm{d}$ $\left(x_{\mathrm{n}}, x_{\mathrm{m}}\right) \ll \mathrm{c}$ for all $\mathrm{n}, \mathrm{m} \geq \mathrm{N}$.

(iii) $(\mathrm{X}, \mathrm{d})$ is called a complete cone metric space if every Cauchy sequence in $\mathrm{X}$ is convergent

Definition 2.6 [8]: Cone $P$ is called minihedral cone if sup $\{\mathrm{x}, \mathrm{y}\}$ exists for all $\mathrm{x}, \mathrm{y} \in \mathrm{E}$ and strongly minihedral if every subset of $\mathrm{E}$ which is bounded from above has a supremum.

Lemma 2.7 [9]: Every strongly minihedral normal cone is regular.

\section{Main results}

Theorem3.1: Let $(X, d)$ be a complete cone metric space and suppose the mapping $T_{1}, T_{2}: X \rightarrow X$ satisfy the contractive condition, $d\left(T_{1} x, T_{2} y\right) \leq K\left[\left(T_{1} x, x\right)+d(x, y)+d\left(T_{2} y, y\right)\right.$ for all $x, y \in X$, where $0 \leq k \leq \frac{1}{2}$.

Then $T_{1}$ and $T_{2}$ have a unique fixed point in $X$. And for any $x \in X$, iterative sequences $\left\{T_{1}{ }^{2 n+1} x\right\}$ and $\left\{T_{2}{ }^{2 n+2} x\right\}$ converse to the common fixed point.

Proof: For each $x_{0} \in X$ and $\mathrm{n} \geq 1$, set $x_{1}=T_{1} x_{0}$ and $x_{2 n+1}=T_{1} x_{2 n}=T_{1}{ }^{2 \mathrm{n}+1} x_{0}$.

Similarly $x_{2 n+1}=T_{2} x_{2 n+1}=\mathrm{T}_{2}^{2 \mathrm{n}+2} x_{0}$. Then we have

$$
\begin{aligned}
d\left(x_{2 n+1}, x_{2 n}\right) & =d\left(T_{1} x_{2 n}, T_{2} x_{2 n-1}\right) \\
& \leq \mathrm{K}\left[d\left(T_{1} x_{2 n}, x_{2 n}\right)+d\left(x_{2 n}, x_{2 n-1}\right)+d\left(T_{2} x_{2 n-1}, x_{2 n-1}\right)\right] \\
& =\mathrm{K}\left[d\left(x_{2 n+1}, x_{2 n}\right)+d\left(x_{2 n}, x_{2 n-1}\right)+d\left(x_{2 n}, x_{2 n-1}\right)\right] \\
\text { So, } \mathrm{d}\left(x_{2 n+1}, x_{2 n}\right) & =\frac{2 k}{1-k} d\left(x_{2 n}, x_{2 n-1}\right) \\
& =h d\left(x_{2 n}, x_{2 n-1}\right) \text { where } h=\frac{2 k}{1-k} .
\end{aligned}
$$

For $n \geq m$

$$
\begin{aligned}
d\left(x_{2 n}, x_{2 m}\right) & \leq d\left(x_{2 n}, x_{2 n-1}\right)+d\left(x_{2 n-1}, x_{2 n-2}\right)+\ldots+d\left(x_{2 m+1}, x_{2 m}\right) \\
& \leq\left(h^{2 n-1}+h^{2 n-2}+\cdots+h^{2 m}\right) d\left(x_{1}, x_{0}\right) \\
& \leq \frac{h^{2 m}}{1-h} d\left(x_{1}, x_{0}\right)
\end{aligned}
$$

Let $0 \ll c$ be given, choose a positive integer $\mathrm{N}_{1}$, such that $\frac{h^{2 m}}{1-h} d\left(x_{1}, x_{0}\right) \ll c$. For allm $\geq \mathrm{N}_{1}$ Thus $d\left(x_{2 n}, x_{2 m}\right) \ll c$, for $n>m$.Therefore $\left\{x_{2 n}\right\}$ is a Cauchy sequence in $(X, d)$. Since $(X, d)$ be a complete cone metric space, there exist $x^{*} \in X$ such that $x_{2 n} \rightarrow x^{*}$. Now choose a positive integer $N_{2}$ such that $d\left(x_{2 n+1}, x_{2 n}\right) \ll \frac{c(1-k)}{3 k}, \mathrm{~d}\left(x_{2 n}, x^{*}\right) \ll \frac{c(1-k)}{3 k}$ and $d\left(x_{2 n+1}, x^{*}\right) \ll \frac{c(1-k)}{3}$ for all $n \geq N_{2}$. Hence for $n \geq N_{2}$ we have,

$$
\begin{aligned}
d\left(T_{1} x^{*}, x^{*}\right) & \leq d\left(T_{1} x_{2 n}, T_{1} x^{*}\right)+d\left(T_{1} x_{2 n}, x^{*}\right) \\
& \leq \mathrm{K}\left[d\left(T_{1} x_{2 n}, x_{2 n}\right)+d\left(x_{2 n}, x^{*}\right)+d\left(T_{1} x^{*}, x^{*}\right)\right]+d\left(x_{2 n+1}, x^{*}\right) \\
& \leq \mathrm{K}\left[d\left(x_{2 n+1}, x_{2 n}\right)+d\left(x_{2 n}, x^{*}\right)+d\left(T_{1} x^{*}, x^{*}\right)\right]+d\left(x_{2 n+1}, x^{*}\right)
\end{aligned}
$$




$$
\begin{aligned}
d\left(T_{1} x^{*}, x^{*}\right) & \leq \frac{1}{1-k}\left[k d\left(x_{2 n+1}, x_{2 n}\right)+k d\left(x_{2 n}, x^{*}\right)+d\left(x_{2 n+1}, x^{*}\right)\right] \\
& \leq \frac{c}{3}+\frac{c}{3}+\frac{c}{3} .
\end{aligned}
$$

Thu, $d\left(T_{1} x^{*}, x^{*}\right) \ll \frac{c}{m}$ for all $m \geq 1$.so,$\frac{c}{m}-d\left(T_{1} x^{*}, x^{*}\right) \in P$ forall $m \geq 1$.

Since $\frac{c}{m} \longrightarrow 0(a s m \rightarrow \infty)$ and $\mathrm{P}$ is closed, $-d\left(T_{1} x^{*}, x^{*}\right) \in P$. But $d\left(T_{1} x^{*}, x^{*}\right) \in P$. Therefore $d\left(T_{1} x^{*}, x^{*}\right)=0$ and so, $T_{1} x^{*}=x^{*}$. So $x^{*}$ is a fixed point of $T_{1}$.

Now if $y^{*}$ is another fixed point of $T_{1}$, Then

$$
\begin{aligned}
d\left(x^{*}, y^{*}\right) \leq & k\left[d\left(T_{1} x^{*}, x^{*}\right)+d\left(T_{1} y^{*}, y^{*}\right)+d\left(x^{*}, y^{*}\right)\right] \\
& =0 .
\end{aligned}
$$

Hence $x^{*}=y^{*}$. Therefore the fixed point of $T_{1}$ is unique.

Similarly, it can be established that $T_{2} x^{*}=x^{*}$. Hence $T_{1} x^{*}=x^{*}=T_{2} x^{*}$. Thus $x^{*}$ is the common fixed point of $T_{1}$ and $T_{2}$.

Theorem3.2: Let $(X, d)$ be a complete cone metric space and suppose the mapping $T_{1}, T_{2}: X \rightarrow X$ satisfy the contractive condition, $d\left(T_{1} x, T_{2} y\right) \leq K\left[\left(T_{1} x, y\right)+d(x, y)+d\left(x, T_{2} y\right)\right.$ for $x, y \in X$, where $0 \leq k \leq \frac{1}{2}$.

Then $T_{1}$ and $T_{2}$ have a unique fixed point in $X$. And for any $x \in X$, iterative sequences $\left\{T_{1}{ }^{2 n+1} x\right\}$ and $\left\{T_{2}{ }^{2 n+2} x\right\}$ converse to the common fixed point.

Proof: For each $x_{0} \in X$ and $\mathrm{n} \geq 1$, set $x_{1}=T_{1} x_{0}$ and $x_{2 n+1}=T_{1} x_{2 n}=\mathrm{T}_{1}{ }^{2 \mathrm{n}+1} x_{0}$. Similarly $x_{2 n+1}=T_{2} x_{2 n+1}=\mathrm{T}_{2}{ }^{2 n+2} x_{0}$. Then we have

$$
\begin{aligned}
d\left(x_{2 n+1}, x_{2 n}\right) & =d\left(T_{1} x_{2 n}, T_{2} x_{2 n-1}\right) \\
& \leq \mathrm{K}\left[d\left(T_{1} x_{2 n}, x_{2 n-1}\right)+d\left(x_{2 n}, x_{2 n-1}\right)+d\left(x_{2 n}, T_{2} x_{2 n-1}\right)\right] \\
& =\mathrm{K}\left[d\left(x_{2 n+1}, x_{2 n-1}\right)+d\left(x_{2 n}, x_{2 n-1}\right)\right] \\
& \leq K\left[d\left(x_{2 n+1}, x_{2 n}\right)+d\left(x_{2 n}, x_{2 n-1}\right)+d\left(x_{2 n}, x_{2 n-1}\right)\right]
\end{aligned}
$$

So, $d\left(x_{2 n+1}, x_{2 n}\right) \leq \frac{2 k}{1-k} d\left(x_{2 n}, x_{2 n-1}\right)$

$$
=h d\left(x_{2 n}, x_{2 n-1}\right) \text {, where } h=\frac{2 k}{1-k} \text {. }
$$

For $n>m$

$$
\begin{aligned}
d\left(x_{2 n}, x_{2 m}\right) & \leq d\left(x_{2 n}, x_{2 n-1}\right)+d\left(x_{2 n-1}, x_{2 n-2}\right)+\ldots+d\left(x_{2 m+1}, x_{2 m}\right) \\
& \leq\left(h^{2 n-1}+h^{2 n-2}+\cdots+h^{2 m}\right) d\left(x_{1}, x_{0}\right) \\
& \leq \frac{h^{2 m}}{1-h} d\left(x_{1}, x_{0}\right)
\end{aligned}
$$

Let $0 \ll c$ be given, choose a positive integer $\mathrm{N}_{1}$, such that $\frac{h^{2 m}}{1-h} d\left(x_{1}, x_{0}\right) \ll c$. for allm $\geq \mathrm{N}_{1}$. Thus, $d\left(x_{2 n}, x_{2 m}\right) \ll c$, for $n>m$. Therefore $\left\{x_{2 n}\right\}$ is a Cauchy sequence in $(X, d)$.

Since $(X, d)$ be a complete cone metric space, there exist $x^{*} \in X$ such that $x_{2 n} \rightarrow x^{*}$. Now choose a positive integer $N_{2}$ such that $d\left(x_{2 n}, x^{*}\right) \ll \frac{c(1-k)}{4}$ and for all $n \geq N_{2}$. Hence for $n \geq N_{2}$ we have,

$$
\begin{aligned}
d\left(T_{1} x^{*}, x^{*}\right) & \leq d\left(T_{1} x_{2 n,}, T_{1} x^{*}\right)+d\left(T_{1} x_{2 n}, x^{*}\right) \\
& \leq \mathrm{K}\left[d\left(T_{1} x_{2 n}, x^{*}\right)+d\left(x_{2 n}, x^{*}\right)+d\left(T_{1} x^{*}, x^{*}\right)+d\left(x_{2 n+1}, x^{*}\right)\right. \\
& \leq \mathrm{K}\left[d\left(x_{2 n+1}, x^{*}\right)+d\left(x_{2 n}, x^{*}\right)+d\left(T_{1} x^{*}, x^{*}\right)+d\left(x_{2 n}, x^{*}\right)+d\left(x_{2 n+1}, x^{*}\right)\right]
\end{aligned}
$$




$$
\begin{aligned}
d\left(T_{1} x^{*}, x^{*}\right) & \leq \frac{1}{1-k}\left[2 k d\left(x_{2 n}, x^{*}\right)+k d\left(x_{2 n+1}, x^{*}\right)\right]+d\left(x_{2 n+1}, x^{*}\right) \\
& \leq \frac{2 c}{4}+\frac{c}{4}+\frac{c}{4} . \\
& =c
\end{aligned}
$$

Thus, $d\left(T_{1} x^{*}, x^{*}\right) \ll \frac{c}{m}$ for all $m \geq 1$.so, $\frac{c}{m}-d\left(T_{1} x^{*}, x^{*}\right) \in P$ for all $m \geq 1$.

Since $\frac{c}{m} \longrightarrow 0($ asm $\rightarrow \infty)$ and $\mathrm{P}$ is closed, $-d\left(T_{1} x^{*}, x^{*}\right) \in P$. But $d\left(T_{1} x^{*}, x^{*}\right) \in P$.

Therefore $d\left(T_{1} x^{*}, x^{*}\right)=0$ and so, $T_{1} x^{*}=x^{*}$.

Now if $y^{*}$ is another fixed point of $\mathrm{T}_{1}$, Then

$$
\begin{gathered}
d\left(x^{*}, y^{*}\right) \leq k\left[d\left(T_{1} x^{*}, x^{*}\right)+d\left(T_{1} y^{*}, y^{*}\right)+d\left(x^{*}, y^{*}\right)\right] \\
=0 .
\end{gathered}
$$

Hence $x^{*}=y^{*}$. Therefore the fixed point of $T_{1}$ is unique.

Similarly, it can be established that $T_{2} x^{*}=x^{*}$. Hence $T_{1} x^{*}=x^{*}=T_{2} x^{*}$. Thus $x^{*}$ is the common fixed point of $T_{1}$ and $T_{2}$.

\section{References}

[1] Huang Gaung, Zhang Xian.” Cone metric spaces and fixed point theorems of contractive Mappings”, J. math. Anal. Appl. 332 (2007) 14681476.

[2] Sh. Rezapour, R. Hamlbarani, "Some notes on the paper- Cone metric spaces and fixedPoint theorems of contractive mappings,"J.Mthe, Anal.Appl. 345(2008) 719-724.

[3] B. Repacki, On fixed point theorems of Maia type, publications De L' institute Mathematique 28 (1980)179-186.

[4] M. G. Maia, Un’Osservazione sullen contrazioni sullemetriche, Ren. Sem. Mat. Univ.Padova 40 (1968)139-143.

[5] S.D. Lin, "A common fixed point theorem in abstract spaces," Indian J. Pure appl. Math. 18(8) (1987) 685-690.

[6] M. S. Khan and M. A. Imdad,"A Common fixed point theorem for a class of mappings", Indian J. Pure appl. Math.14, (1983), $1220-1227$.

[7] R. Tiwari and D.P.Shukla, "Fixed point results in cone metric spaces", Int .J. of mathematical Archive 3(8), (2012) 3075-3078.

[8] K. Deimling, Nonlinear Functional Analysis springer-Verlag, Berlin, Heidelberg, New York, Tokyo,(1985).

[9] T. Abdeljawad and E. Karapinar, "Quasi- cone metric spaces and generalizations of Caristi Kirk's theorem," Fixed point theory Appl., 2009 doi: $10,1155 / 2009 / 574387$.

[10] T. Abdeljawad," Completion of cone metric spaces". Hacettepe J. Math. Stat. 39(1), (2010) 67- 74. 